\title{
DOUBLE CONGESTIVE GLAUCOMA AND THE RESPONSE TO DIATHERMY
}

\author{
BY \\ J. EDWARd Martin \\ SENIOR RESIDENT OFFICER, BRISTOL EYE HOSPITAL
}

I AM privileged by the courtesy of Mr. Walbank to submit the details of this case, which may interest others computing the $\vec{\omega}$ value of diathermy as an ancillary form of treatment in the $\frac{\rho}{\partial}$ reduction of increased intra-ocular tension. It is of unusual interesto in that, in the same individual, one eye was used as a control $\overrightarrow{0}$ against the other, both being in a state of hypertension as the $\overrightarrow{-}$ result of similar pathological sequences.

Since I was in charge of the Wards as well as of the Diathermys Department, I had the opportunity of controlling treatments from $\vec{c}$ the time of admission. In this case no previous treatment had been given.

The apparatus employed was the Moorfields pattern made by Messrs. Weiss, the active electrode being of lead as adopted by $\vec{c}$ Mr. F. W. Law. 1 .

I use three layers of gamgee, wrung out in normal saline, in the form of pads between the active electrode and the lids.

The milliampère-meter readings mentioned are the mean, the output being slowly increased during the first minute up to abouto 500 to $600 \mathrm{~m}$.a. and then reduced at the patient's direction, as the⿳ conductivity increases with the accumulating thermal response.

Tonometry was carried out with a Schiötz instrument with a concave piston end.

S. C., aged 63 years, a packing case maker, of poor physique, and of toxic appearance, gave the history during the last six oro seven months of recurrent mild attacks of pain above both eyes; but more so in the right, accompanied by dimness of vision and lasting two to three days with apparent recovery during the intervals.

Vision had diminished during the previous week so that on Monday he was unable to go to work, while on Tuesday hes developed severe pain in both eyes. On Wednesday morning following a bout of vomiting he was admitted to hospital complaining of pain and dimness in both eyes. Leeches were appliedo to the right temple and a purge given.

A central leucoma of the right cornea, lens opacity and oedeman of the epithelium in both eyes rendered media examination $\omega_{-}^{\omega}$ impossible. The anterior chambers were shallow. The visuaf acuity recorded may or may not be relative. No corrections were worn. 
Double Congestive Glaucoma

The following table shows the sequence of events :RIGHT EYE

LEFT EYE

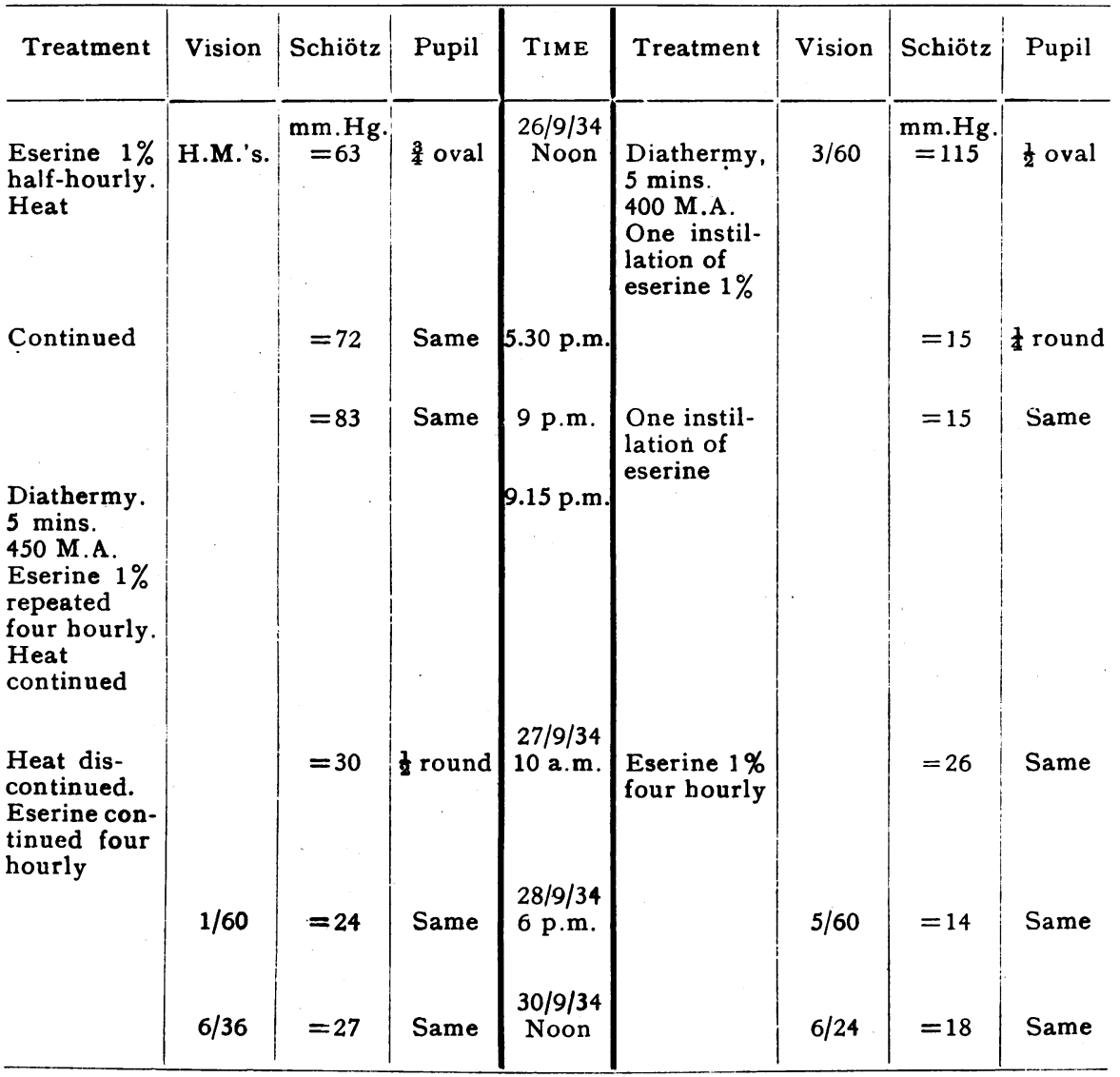

On September 30, the result enabled further ophthalmoscopic examination to be made, showing the left vitreous to be clear, and cupping of the disc. Sufficient detail was seen of the right media to exclude intra-ocular haemorrhage.

The blood pressures were $120 / 90$. The fields were slightly concentrically contracted.

Here the interest, from the pre-operative preparation point of view, ends.

\section{REFERENCE}

Law, F. W.-Trans. Ophthal. Soc. U.K., Vol. LIII, p. 474, 1933. 